\section{Open Notes Are Here: Are We Ready?}

A s of April 1, 2021, "Open Notes and Results Transparency" as required by the 21st Century Cures Act was implemented. Gasp! Now my patients can read exactly what I say about them! I'm accustomed to using the record for professional communication, not lay communication. What if I get something wrong or inadvertently say something demeaning? What if something I write erodes trust or interferes with our relationship? Yikes!

Actually, I'm not worried about any of this. In oncology, patients gathering up their own records and bringing them to me for review has always been routine. So, patients have always been able to see what we write, and I have always been sensitive to that. Of course, electronic access makes it easier. Remember the old days when patients had to wait in the medical records department for personnel there to dredge up reams of paper to copy? In the new world, both we and the patients can more easily find the information they want.

At the same time, I thought brushing up on my written communication techniques might be prudent. So when our Chief Medical Officer sent out tips, I paid attention. And you know what? It was helpful! For instance, I had not thought to avoid acronyms like SOB (for shortness of breath) and F/U (for follow up). Those terms have a WHOLE different context in lay communication! In addition, simple adjectives we commonly use, like "noncompliant" and "disheveled," can seem very derogatory.

Ultimately, I think the way forward is easy. Avoid acronyms and consider the impact of your words as if you know the patient is going to read it. And of course, be gracious about commenting on care rendered by other providers. Just provide the facts-no opinion is really needed!

Pilot programs where Open Notes has been implemented suggest that few patients actually access these notes but those who do appreciate the opportunity to review the plan shown in the note. After all, we know that much of what we say is forgotten after the visit.

Although Open Notes may be more problematic for providers in other areas of medicine, especially those in which litigation is more common, my hope is that more transparency is a good thing and that more engagement and involvement by patients will lead to better outcomes. Remember, if a patient finds an error, we can fix it. After all, we all want the record to be accurate.

Throughout the recent pandemic, many have repeated the mantra, "Be kind; be caring; be safe." It strikes me that these are good words to live by regardless of external threats, and they certainly apply to Open Notes. So, try to embrace Open Notes with a positive attitude. Just follow a few simple principles and it will be OK!

WHAT DO YOU THINK? To submit a Letter to the Editor, email JNCCN@nccn.org or log into www.editorialmanager.com/JNCCN.

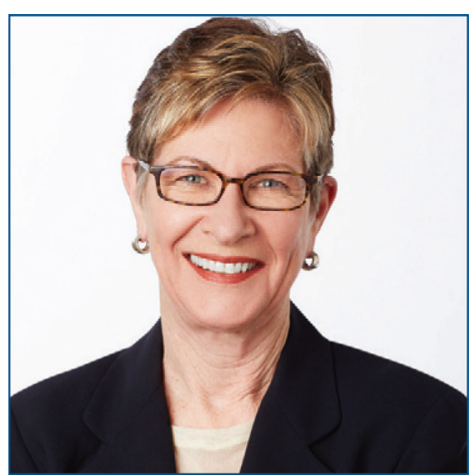

MARGARET TEMPERO, MD

Margaret Tempero, MD, is a Professor of Medicine and Director of the UCSF Pancreas Center and editor-in-chief of JNCCN. Her research career has focused on pancreatic ductal adenocarcinoma, especially in the area of investigational therapeutics. Dr. Tempero has served on the ASCO Board of Directors and as ASCO President. She currently serves on the ASCO Conquer Cancer Foundation Board. She codirected the AACR/ASCO Methods in Clinical Cancer Research and taught this course and similar courses in Europe and Australia. She was founding Chair of the $\mathrm{NCl}$ Clinical Oncology Study Section and served as a member and Chair of the $\mathrm{NCl}$ Board of Scientific Counselors Subcommittee A. She is a member of the Scientific Steering Committee and Chair of the Clinical and Translational Study Section for the Cancer Prevention \& Research Institute of Texas. She is or has been on the Scientific Advisory Boards of the Lustgarten Foundation, the Pancreatic Cancer Action Network, the V Foundation, The Alberta Canada Cancer Board, and the EORTC. She served as a member of the Oncology Drug Advisory Committee for the FDA. She has served as Deputy Director and Interim Director for the UNMC Eppley Cancer Center. She is Chief Emeritus of the Division of Medical Oncology at UCSF. She served as the founding Deputy Director and was later Director of Research Programs at the UCSF Helen Diller Family Comprehensive Cancer Center.

\section{doi: 10.6004/jnccn.2021.0024}

The ideas and viewpoints expressed in this editorial are those of the author and do not necessarily represent any policy, position, or program of NCCN. 